\title{
A história da educação no Hospital Pequeno Príncipe e a formação continua dos professores
}

\author{
Ana Carolina Venâncio ${ }^{1}$ \\ Itamara Peters ${ }^{2}$ \\ Mariana Saad Weinhardt Costa ${ }^{3}$
}

\begin{abstract}
RESUMO
O presente estudo descreve os aspectos históricos da educação de crianças e adolescentes hospitalizados, debatendo o modo como esse direito vem sendo organizado e os desafios de formação docente enfrentados para que o exercício legal se concretize e se efetive. Trata-se de uma pesquisa de caráter qualitativo descritivo, que elenca por amostragem as práticas desenvolvidas e o modo como o direito à educação da criança hospitalizada são garantidos por uma instituição filantrópica de Curitiba. A pesquisa descrita evidencia os aspectos da formação de docentes e educadores do Hospital Pequeno Príncipe tomando como base os estudos desenvolvidos durante a elaboração do projeto político pedagógico do Setor de Educação e Cultura do referido hospital e sua implementação.
\end{abstract}

PALAVRAS-CHAVE: Direito à Educação Hospitalar. Formação docente. Desafios para o Brasil.

The history of education at the Litle Prince Hospital and the continuing training of teachers

\begin{abstract}
This study describes the historical aspects of the education of hospitalized children and adolescents, discussing how this right has been organized and the challenges of teacher training faced in order for the
\end{abstract}

\footnotetext{
${ }^{1}$ Doutora em Educação pela UFPR, Curitiba, Paraná, Brasil. Orcid: https://orcid.org/0000-0001-6804-8711. E-mail: anavenancio2704@gmail.com.

${ }^{2}$ Doutoranda em Letras na UFPR, Curitiba, Paraná, Brasil. Orcid: https://orcid.org/0000-0002-0268-6777. E-mail: itamarapeters@gmail.com.

${ }^{3}$ Mestra em Educação - PUC - PR, Curitiba, Paraná, Brasil. Orcid: https://orcid.org/0000-0001-6411-5059. E-mail: marianasw@uol.com.br.
} 
legal exercise to take place and be ephemeus. This is a descriptive qualitative research, which lists by sampling the practices developed and how the right to education of hospitalized children are guaranteed by a philanthropic institution in Curitiba. The research described highlights the aspects of the training of teachers and educators of the Litlle Prince Hospital based on the studies developed during the elaboration of the political pedagogical project of the Education and Culture Sector of the aforementioned hospital and its implementation.

KEYWORDS: Right to Hospital Education. Teacher training. Challenges for Brazil.

La historia de la educación en el Hospital Pequeño Príncipe y la formación continua de los maestros

\section{RESUMEN}

Este estudio describe los aspectos históricos de la educación de los niños y adolescentes hospitalizados, discutiendo cómo se ha organizado este derecho y los desafíos de la formación del profesorado a los que se enfrenta para que el ejercicio legal se lleve a cabo y sea efemo. Se trata de una investigación cualitativa descriptiva, que enumera mediante el muestreo de las prácticas desarrolladas y cómo el derecho a la educación de los niños hospitalizados está garantizado por una institución filantrópica en Curitiba. La investigación descrita destaca los aspectos de la formación de profesores y educadores del Hospital Litlle Prince a partir de los estudios desarrollados durante la elaboración del proyecto pedagógico político del Sector de Educación y Cultura del mencionado hospital y su implementación.

PALABRAS CLAVE: Derecho a la educación hospitalaria. Formación del profesorado. Desafíos para Brasil.

$$
* * *
$$

\section{Introdução}

O presente texto busca apresentar como se dá a organização do atendimento à educação e à cultura no Hospital Pequeno Príncipe, em 
Curitiba, Paraná, Brasil pelo viés da formação da equipe de educadores. O hospital traz a concretização de projetos educativos tendo o acesso ao processo de educação como direito incontestável das crianças e jovens em tratamento de saúde. A proposta educativa do Setor de Educação e Cultura do Hospital vem sendo organizada ao longo da existência do setor.

Entende-se que o Projeto Pedagógico do Setor se define como uma "obra aberta", ou seja, o processo pedagógico se cria e recria de acordo com as demandas educativas que lhe são apresentadas, entretanto, esse processo se dá considerando determinados princípios educativos que visam a referenciação da prática pedagógica desenvolvida na instituição.

Defende-se ainda que esta articulação de Educação e Cultura se dê também entre saúde e educação, numa abordagem multidisciplinar compartilhada entre equipes, que permite aos sujeitos a vivência dos direitos a saúde e educação de forma integrada, conforme o que determina a legislação. Desta maneira, o planejamento e operacionalização de ações particularizadas, possíveis a partir da construção de um plano de trabalho com base nas necessidades contextuais e de aprendizagem de sujeitos ${ }^{4}$ singulares, permite não só a continuidade dos estudos, mas a convivência e a participação social necessária ao desenvolvimento e aprendizagem humana e a vivência de uma cidadania de fato e não somente no plano ideal.

\section{Metodologia de pesquisa}

Trata-se de uma pesquisa qualitativa que envolve um estudo de caso (focada no contexto de atuação) de cunho etnográfico (visa a descrição de um modo particular de organização, trazendo a prática dos sujeitos no seu locus de ação), ou seja, investiga como se dá a formação de

\footnotetext{
${ }^{4}$ Crianças e adolescentes em tratamento de saúde, matriculados ou não em escolas públicas ou privadas de todo o país e que ainda não concluíram a Educação Básica.
} 
docentes no seu e para o seu contexto de atuação, neste caso a docência em programas de escolarização hospitalar.

\section{Uma história centenária}

A história do Hospital Pequeno Príncipe completou em 2019, um século de existência. É uma história de motivação e preocupação com o bem-estar do outro, o hospital nasceu do olhar cuidadoso e atento de um grupo de mulheres curitibanas que tocadas pelos fatos da Primeira Guerra Mundial e por movimentos de criação da Cruz Vermelha, rede internacional de atendimento a saúde dos menos favorecidos, mobilizaram-se para criar um atendimento a saúde da população de baixa renda na cidade de Curitiba, em especial o atendimento as crianças. Tal mobilização ganhou força e sucesso culminando no primeiro ambulatório infantil com endereço fixo, inaugurado em maio de 1919, no qual as crianças eram atendidas gratuitamente e recebiam também seus medicamentos.

A partir da inauguração do ambulatório surgiu, ainda em 1919, o Instituto de Higiene Infantil e Puericultura, inaugurado em 26 de outubro do mesmo ano e que já em fase inicial se constituiu em referência as mães tanto no atendimento de bebês como no ensino dos cuidados com a infância, sendo chamado de Posto Infantil. É desta proposta que nasceu o Hospital Pequeno Príncipe, conjugando nomes, histórias de cuidado com a infância e pesquisa.

Atualmente o Complexo Pequeno Príncipe se constitui em um centro de referência e assistência à saúde, ensino e pesquisa que atende crianças e jovens da região e de outros estados, congregando o Hospital Pequeno Príncipe, as Faculdades Pequeno Príncipe e o Instituto de Pesquisa Pelé Pequeno Príncipe, tendo como mantenedora a Associação Hospitalar de Proteção à Infância Dr. Raul Carneiro.

Ao longo da história o Hospital se concretiza como um espaço educador, desde sua fundação há uma preocupação com o ato de educar e 
de humanizar que se revela, igualmente, no âmbito da formação de profissionais para atendimento ao público infantil e com a educação dos cuidados para com a infância. Segundo Carreira (2016, p.24) "para a equipe do Hospital o acesso à informação e à educação amplia as possibilidades das pessoas cuidarem melhor de sua própria saúde”, assim como da saúde das crianças e dos adolescentes. "Educar para a saúde passou a ser um dos eixos transversais da instituição”.

Desde o princípio a instituição volta seu olhar para o cuidado e a atenção humanizada ao seu público: crianças, adolescentes e mães formando profissionais em diversas áreas como apresentamos na figura a seguir.

Figura 1: Ações educativas do Hospital Pequeno Príncipe

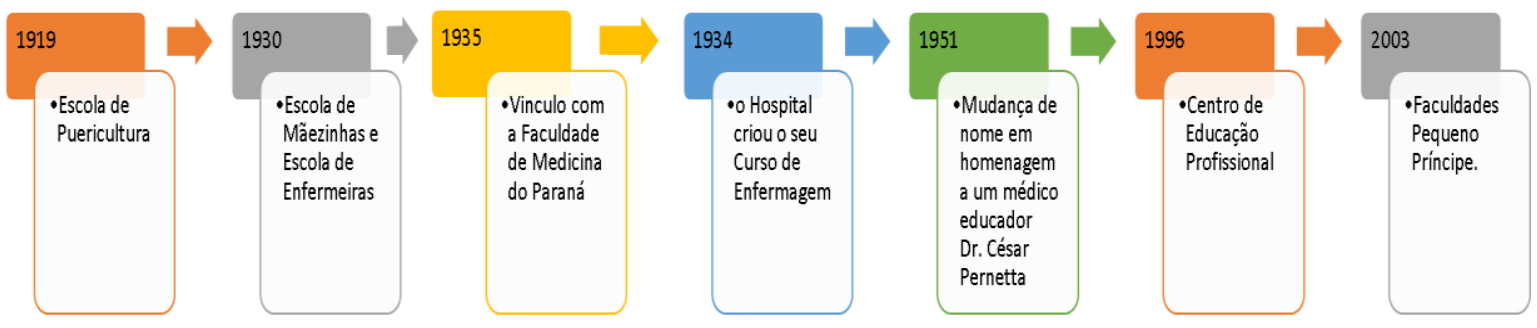

Fonte: os autores, 2020.

As ações educativas do hospital se ampliam e o processo de ensinar vai além das profissões médicas, nesta perspectiva há a compreensão de que a relação de cuidado envolve a tríade ensino, pesquisa e assistência para que a instituição fosse capaz de oferecer um atendimento integral e de qualidade a quem necessita dele.

Em 1967, com nova mobilização da sociedade curitibana, foi iniciada, em um terreno doado, a construção de um novo prédio nos fundos do Hospital de Crianças César Perneta. A nova unidade, inaugurada em 1971, recebeu o nome de Hospital Pequeno Príncipe, e foi especialmente pensada para o público que iria atender. Foi incorporada ao prédio mais antigo por um túnel que contempla a linha do tempo do hospital e assim as duas unidades passaram a compor um único hospital. 
Neste processo de cuidado, a instituição investiu de modo pioneiro em outros serviços como a psicologia, a humanização, a assistência social, a família participante, o voluntariado e a educação e cultura criando departamentos responsáveis por cada um destes serviços. "O Pequeno Príncipe é um hospital educador porque concebe e exercita a prática de democratização do conhecimento de todas as formas possíveis para a população." (CARREIRA, 2016, p.33).

Pautando-se nessa premissa o hospital e seus profissionais preocupam-se também com o processo educacional dos pequenos e pequenas que são afastados da escolarização em virtude de um tratamento de saúde. Com essa preocupação e as ações voltadas para o seu público, o hospital abre portas a uma nova proposta: a educação no espaço hospitalar.

\section{Do hospital educador ao direito à educação e cultura}

As ações de um Hospital educador levaram a criação do "Projeto Mirim de Hospitalização Escolarizada" em 1987, desenvolvido pela então assistente social Margarida M. T. F. Muggiati. O projeto inicia-se com objetivo de minimizar os problemas decorrentes da longa hospitalização de crianças e adolescentes: o stress causado pela hospitalização, a depressão, o afastamento da família e a interrupção da trajetória escolar, entre outros. Inicialmente o projeto contava apenas com profissionais do hospital, porém a grande demanda de atendimentos exigiu a busca de uma rede de apoio.

A rede de apoio foi formada a partir de convênios estabelecidos com as Secretarias de Educação do Estado (1988) e Município (1990), o programa "Hospitalização Escolarizada" foi o marco da criação do Setor de Educação e Cultura, que se institui oficialmente em 2002, com o propósito de ampliar e fortalecer o acompanhamento escolar de crianças e adolescentes hospitalizados. 
Desde o início de suas atividades há por parte de Setor de Educação e Cultura uma preocupação com a educação formal e com a ampliação de repertórios linguísticos, históricos, culturais, artísticos, entre outros; tanto das crianças e adolescentes, como de suas famílias e colaboradores do hospital.

A ampliação dos serviços constitui uma grande rede de ações interligadas, nela estão as atividades de leitura e contação de histórias, as oficinas de arte, música, teatro, fotografia, entre outras, e os jogos, que complementam o processo educativo desenvolvido pelos professores.

Com o intuito de formalizar ainda mais suas ações o Setor passa a criar um sistema de registro das atividades desenvolvidas, cada criança é acompanhada com uma ficha individual na qual são descritas todas as atividades escolares e culturais que participou durante seu período de internamento; ao final dos atendimentos professores e educadores elaboram um parecer descritivo e organizam um portifólio das atividades que são encaminhadas para a escola de origem da criança. Tal organização visa garantir plenamente o acesso a educação e o retorno desse processo a escola de matrícula da criança/adolescente, a fim de que a continuidade da escolarização, mesmo em face a doença, seja garantida e possível.

O investimento do Hospital e dos profissionais em prol da educação no espaço hospitalar pode ser observado com mais clareza na figura abaixo que traz a linha do tempo das ações desenvolvidas em prol da garantia do direito à educação das crianças e adolescentes que frequentam o Hospital para tratar de sua saúde, mas que também têm a possibilidade de ter acesso à educação e à cultura de modo sistemático, planejado e pensado para elas. 
Figura 2: História da educação no Hospital Pequeno Príncipe

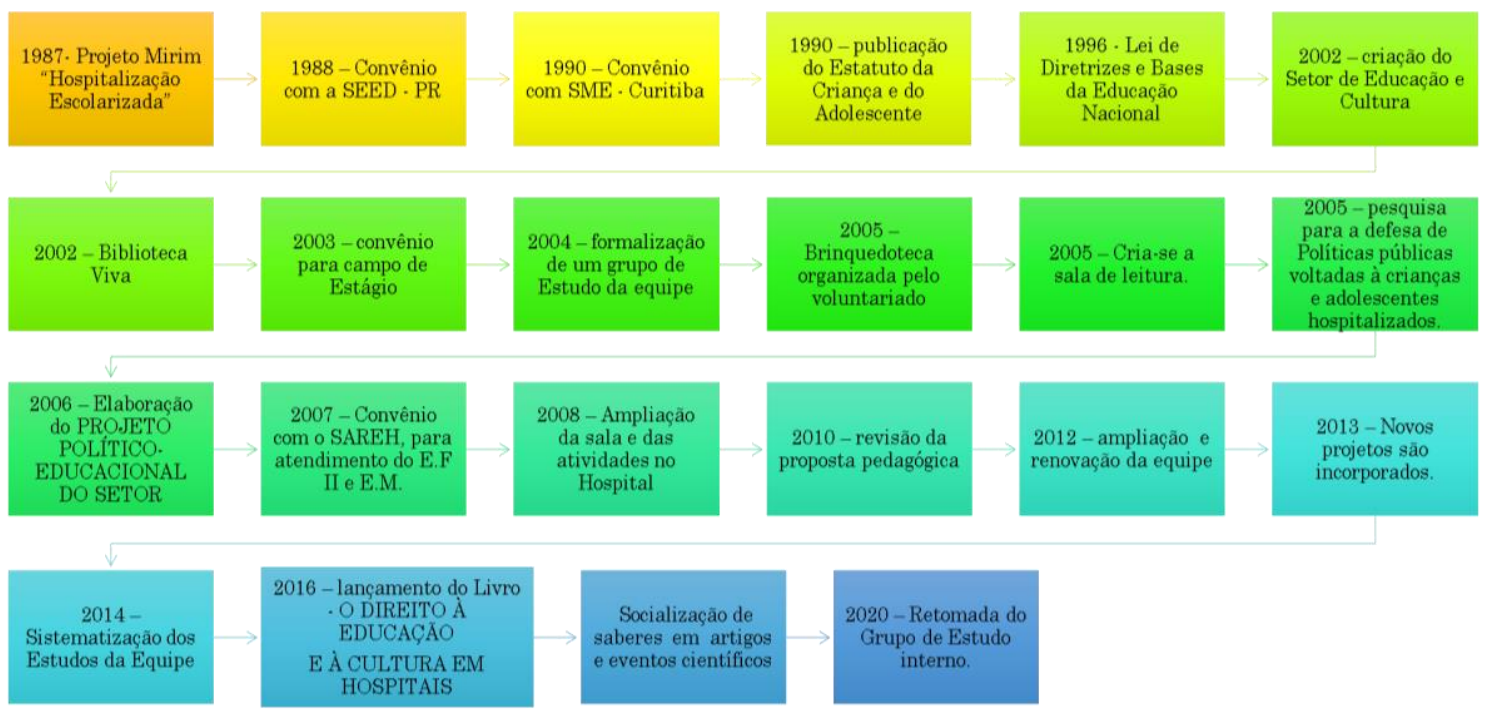

Fonte: os autores, 2020.

Desde o início do Projeto Mirim a institucionalização de um Setor de Educação e Cultura no Hospital Pequeno Príncipe há um grande investimento tanto das equipes que foram constituindo esse setor como da instituição em formar seus profissionais e buscar a excelência nas propostas educativas.

\section{Principios teóricos}

O hospital se constitui como ambiente cuja significação social está atrelada à representação de cuidados somente de saúde. Entretanto, há escolas em hospitais e, crescentemente, há professores que atuam junto aos estudantes em internação ou tratamento ambulatorial buscando garantirlhes direitos conjugados: de saúde e educação.

Apesar de a educação hospitalar ser modalidade ainda pouco discutida academicamente, uma modalidade ainda em construção teórica e prática em solo brasileiro, há leis que garantem o direito dos educandos a ter a continuidade dos estudos, independente das condições de saúde, a saber (Constituição Federal 188, art.205; Decreto Lei n.1044/69, art. 1º que dispõe sobre tratamento excepcional para alunos portadores de afecções; Lei $n$. 
8.069/90; Resolução n. 41/95; Lei n. 9.394/96; Resolução n.02/01 - CNE/CEB; Documento intitulado Classe hospitalar e atendimento pedagógico domiciliar: estratégias e orientações, editado pelo MEC, em 2002. Política Nacional de Educação Especial na Perspectiva da Educação Inclusiva de 2008. Alteração da Lei n. 9.394/96 pelo texto da Lei $n^{0} 13.716$, de 24 de setembro de 2018). Estas diretrizes legais apontam para a necessária atenção que merece, quem está privado, por tratamento de saúde crônico ou prolongado, a ter direitos básicos garantidos, em especial o direito à educação.

Entendendo-se a educação como possibilidade de participação social e política que incita a emancipação dos sujeitos. Percebe-se portanto, que para além das diversas questões que complexificam o ambiente escolar formal, nos ambientes de ensino diferenciados há desafios idênticos e outros que se configuram a partir da singularidade destes novos ambientes que se estruturam, em geral, por meio da militância dos que neles atuam.

No hospital iniciamos nossa prática com um diálogo com a família e estudante. Buscamos conhecer o contexto de vida, situação atual e colher dados sobre a escolarização que nos permitam entender a trajetória daquele/a que será por nós atendido. Neste momento, acolhemos a família, a convidamos a ser nossa parceira, e o/a estudante a imergir na escolarização de forma ativa, porém diferenciada, tomamos seus interesses, curiosidades e seus conhecimentos prévios como material que irá modelar o plano de trabalho a ser desenvolvido, ainda que sigamos as orientações da equipe escolar no que tange ao currículo a ser vivenciado.

Mantemos estreito contato com as escolas de origem, acolhemos as equipes, muitas vezes somos nós, professores do hospital, que apresentamos o educando ao professor e a sua turma, pois muitas vezes o/a estudante nunca foi a escola ou está ausente em tempo prolongado. Desta forma, estreitamos ou criamos vínculos, entre professores, alunos e aprendizagem, demonstrando o prazer de aprender por meio da construção de relações dialógicas onde os sentido de ensinar e aprender vão tecendo redes de afeto, de esperança e amorosidade que culminam em aprofundamento de 
conhecimentos e ressignificação de práticas em uso, ampliando repertórios (tanto dos alunos quanto dos profissionais que com eles atuam).

Neste percurso, atuamos de forma multiprofissional, estabelecendo parceria com professores, pedagogos, direção escolar, mas, também e necessariamente, com as equipes de saúde que atendem a criança/jovem. Isto porque a rotina no hospital é absolutamente diversa da sala de aula. Dependemos de uma articulação entre profissionais que culmine na promoção da qualidade de vida de quem é atendido

Todo o trabalho pauta-se na singularização dos planos de aula e prevê flexibilização curricular. A atuação envolve toda a equipe de assistência a saúde e as famílias para estabelecimento de diálogo e parceria em prol do estudante atendido, bem como envolve a equipe da escola de origem e demais profissionais que atendem o estudante no hospital e em domicílio.

Ao propor uma relação estreita entre saúde, educação e cultura nos dispomos a aproximar conhecimentos, retomando uma relação necessária no cuidado integral dos sujeitos. Tal relação articula uma troca de saberes que emerge do contexto e o reconhecimento de que as duas áreas podem contribuir mutuamente com conhecimentos que agregam valor a relação entre saúde e educação, considerando-se, neste percurso, os planos humano, político e didático desta relação.

Relembramos que a educação tem o papel de buscar diferentes linguagens, recursos e formas de atingir objetivos que visam às mudanças de comportamento social. Assim, aliar os conhecimentos da saúde em busca de objetivos comuns se torna uma tarefa que contempla as duas áreas na missão de consolidar-se uma postura voltada para a intervenção precoce e o desenvolvimento de melhores resultados nessa ação de identificação, estímulo e acompanhamento dos processos da saúde. A justificativa desta articulação recai sobre o fato de que "Educação e saúde constituem um campo epistêmico de expressiva relevância para a qualidade de vida humana e social.” (RANGEL, 2009, p. 59). 
Defende-se a premissa de que articular educação e saúde pode se constituir em medida para potencializar práticas afins no intuito de melhorar padrões de qualidade de vida de quem necessita de cuidados integrados, sob a compreensão de que:

\begin{abstract}
A pedagogia é campo teórico que reúne os fundamentos e os subsídios das ciências aplicadas à educação. A educação, portanto, é tema e objeto dos estudos pedagógicos, observandose, especialmente, que a sua essência, a sua substância encontram-se nos valores de formação humana e social.[...] É nessa perspectiva de valores que se compreende a saúde como tema educativo, de formação humana e social, no interesse de que possa também ser entendida e reivindicada como direito fundamental da vida cidadã e parte essencial da dignidade humana. (RANGEL, 2009, p. 60/61).
\end{abstract}

A dimensão humana da inter-relação entre saúde e educação refere-se à finalidade do processo epistêmico de produção do conhecimento e das relações instituídas neste movimento, este compreendido dentro de uma proposta essencialmente humanizante “(...) tanto na perspectiva de sua aplicação social, no interesse da qualidade de vida, como na perspectiva dos valores humanizantes que irão orientar a prática desses profissionais." (RANGEL, 2009, p. 61). O plano humano deveria estar, portanto, presente na formação dos profissionais de saúde e educação, favorecendo o desenvolvimento da sensibilidade, atenção e acolhimento, fatores que detém potencial para sustentar uma postura dialógica que gera e incita atitudes de colaboração, incentivo e inclusão, proporcionando uma melhor organização dos ambientes e uma prática assentada em princípios éticos de acolhimento e amorosidade.

Quanto ao plano político das práticas de educação e saúde, a mesma situa-se no compromisso, "que é dos governos e dos educadores, com o conhecimento a ser garantido no processo de formação, entendendoo como direito dos alunos e essência dos cursos de formação, assim como se encontra na compreensão social e política da saúde" (RANGEL, 2009, p. 62). A ampliação do conceito de qualidade de vida, associado a este compromisso, é um dos pilares de pesquisas contemporâneas e funda-se 
no dever do Estado em "garantir o direito as condições e recursos necessários a essa qualidade" (RANGEL, 2009, p. 62).

A dimensão didática refere-se ao ato de ensinar e aprender, prática que se efetiva na relação entre professores e alunos, assim como na relação entre o profissional da saúde e as pessoas a quem atende.

A didática tem, como objeto, o processo de ensinoaprendizagem. Esse processo, que incorpora objetivos, meios, conteúdos e contexto, nos quais o conhecimento é compreendido, elaborado, aplicado, requer, também, motivação e disposição dos sujeitos que o praticam. (RANGEL, 2009, p. 62).

As aulas são, então, momentos de encontro entre sujeitos que aprofundam conhecimentos por meio de uma postura de pesquisa e análise da realidade, de forma dialógica e respeitosa. Nossos princípios teóricos pautam-se em um rol de educadores progressistas que tomam a educação como um processo aberto, dialógico e construído coletivamente. Consideramos que professor e estudantes são sujeitos do ato de conhecimento e devem participar dele ativamente. Em função disso, trabalha-se com o método dialógico pautado essencialmente no estudos de Paulo Freire.

Freire, nas suas diversas obras, expressa a sua compreensão de educação popular vinculada às ações com os oprimidos, propõe uma metodologia que facilite o processo de emancipação do indivíduo e da sociedade, na esperança de superação da opressão, exploração e desigualdade social. Nessa perspectiva, Freire (2000, p.43) situa que uma das primordiais tarefas da educação crítica radical libertadora (popular) "é trabalhar a legitimidade do sonho ético-político da superação da realidade injusta”. Assim, a educação popular defendida pelo autor é aquela que persegue o sonho da construção de uma sociedade justa, equânime. E é a partir destas considerações que o modo de ensinar vem sendo discutido. 
[...] reinventando-se sempre com uma nova compreensão do poder, passando por uma nova compreensão da produção, uma sociedade em que a gente tenha gosto de viver, de sonhar, de namorar, de amar, de querer bem. Esta tem que ser uma educação corajosa, curiosa, despertadora da curiosidade, mantenedora da curiosidade. (FREIRE, 2001, p.101).

Pensar em educação, e em especial na educação em um ambiente diferenciado, no qual há inúmeros fatores conjugados que lhe conferem singularidade e uma estrutura e funcionamento próprios, exige uma concepção educativa que vá além dos domínios e das paredes da escola, em especial da escola de bases tradicionais, ainda presente e atuante mesmo frente a mudanças sócio histórico culturais que sinalizam a urgência de novos modelos educativos. E é com esta visão de educação que este texto propõe pensar uma prática educacional que fomente no sujeito seu protagonismo, ensinando-lhe a ter voz, tornando-o copartícipe na construção do conhecimento e no movimento contínuo de sua reinvenção.

Para Paulo Freire a educação é baseada no diálogo e na interação entre professor e aluno. E é nesta perspectiva que entendemos e atuamos na Educação Hospitalar. Desse modo, o educador tem um papel de destaque como mediador entre o mundo do conhecimento e o próprio aluno, cabe ao educador ser agente de transformação social, articulando teoria e prática, possibilitando uma reflexão da ação praticada e, consequentemente, a reflexão dos desdobramentos desta ação. Sendo assim: a "relação dialógica proposta por Freire (1996) se estabelece no hospital como uma nova forma de relação que inclui a criança e o jovem em tratamento de saúde em um "contexto de saber/cultural sistematizado" estabelecendo um processo de acesso, vivência e desenvolvimento da consciência crítica durante sua vivência de hospitalização.

O diálogo é uma questão determinante para o encontro das vozes do educador e do educando, isto é, uma condição de ensinar, de aprender e de constituir identidades. Tomamos na Educação Hospitalar o diálogo como centro de todas as ações educativas e saímos dele para o desenvolvimento de 
propostas de ensino pautadas nas necessidades específicas de cada sujeito envolvido nesta proposta. Compreendemos que é preciso reconhecer e respeitar os diferentes tempos dos sujeitos, procurando estabelecer relações necessárias à constituição de conhecimentos e valores. Isto se conquista por meio da interação relacionada ao eu-outro presente na mediação qualitativamente comprometida com um aprendizado crítico, libertador.

$\mathrm{O}$ ato de aprender está diretamente relacionado à função social que o sujeito exerce e às experiências individuais, intimamente relacionadas com o modo de pensamento que o sujeito possui, portanto, aprender não é "repetir a lição" memorizada mecanicamente, vai muito além. (FREIRE,1994, p. 33.).

Pensando nisto, Freire afirmou ainda que os aspectos históricosociais e as diferenças individuais do educando devem ser considerados, uma vez que ele é um ser histórico e se constrói nas relações com os outros homens e com o mundo, partindo do pressuposto de que cada sujeito possui uma configuração única das experiências vivificadas. Visto que a educação só acontece por meio das relações sociais estabelecidas com a comunidade vivida, acredita-se na educação hospitalar emancipada da escola. Que tenha identidade própria, ou seja, que possua um referencial teórico-metodológico que lhe dê base e credibilidade de ação. Tendo claro que isso não significa negar a escola, mas sim reconhecer novos espaços de sistematização do conhecimento e que estes espaços podem representar um modo diferenciado de tratar o conhecimento e avançar tanto em termos de metodologias e didáticas como de teorias sobre os processos educacionais. Aqui ressaltando-se, em paralelo, a necessidade atual de reinvenção dos espaços escolares formais, tendo em vista tanto o objetivo de promover uma educação de todos e para todos, quanto por conta dos avanços tecnológicos e das novas relações com a informação construídas num mundo onde o aparato tecnológico ganha destaque.

Compreende-se também que, além de diálogo e reflexão, o trabalho do professor/educador é comprometer-se com a diversificação de 
metodologias e com um planejamento pautado na personalização do ensino fornecido. Sob compreensão de que o planejamento e execução das aulas devem ser pensados no sentido de poder criá-los mediante contrato com o sujeito do diálogo, sem sua imposição como forma de fazer, como instrumento de poder. Ou seja, a educação não pode ser uma relação hierarquizada, mas uma relação horizontal, dialógica e amorosa, de encontro entre sujeitos.

Compreendemos e concordamos com a função do professor como agente social como define Imbernón (2011, p.46) “os professores podem ser verdadeiros agentes sociais, capazes de planejar e gerir o ensinoaprendizagem, além de intervir nos complexos sistemas que constituem a estrutura social e profissional". É neste sentido que se reflete o modo de agir e de ensinar, buscando as bases de ensino e aprendizagem para então definir metodologia de trabalho num ambiente diferenciado em que o plano de ação docente é móvel, desestabilizado e passível de múltiplas alterações.

Entendemos, de acordo com Freire (1994), que não se pode encarar a educação a não ser como um que fazer humano. Fazer que ocorre no tempo e no espaço, entre os homens, em sua relação dinâmica uns com os outros. E é a partir desta ideia que a educação hospitalar se fundamenta e busca o que fazer. Porém, um que fazer que vá além do óbvio e do escolarizar tradicional, tomando como base do seu agir os pressupostos teóricos de Freire:

Não pode existir uma teoria pedagógica, que implica em fins e meios da ação educativa, que esteja isenta de um conceito de homem e de mundo. Não há, nesse sentido, uma educação neutra. Se, para uns, o homem é um ser da adaptação ao mundo (tomando-se o mundo não apenas em sentido natural, mas estrutural, histórico-cultural), sua ação educativa, seus métodos, seus objetivos, adequar-se-ão a essa concepção. Se, para outros, o homem é um ser de transformação do mundo, seu que fazer educativo segue outro caminho. Se o encaramos como uma "coisa", nossa ação educativa se processa em termos mecanicistas, do que resulta uma cada vez maior 
domesticação do homem. Se o encaramos como pessoa, nosso que fazer será cada vez mais libertador. (FREIRE, 1997, p.07).

Na educação hospitalar a proposta de Paulo Freire se mostra concreta na medida em que todo o processo educativo contempla o diálogo e a bagagem de conhecimentos que o estudante já nos apresenta. Pois a dinâmica da aprendizagem se dá através de interações mútuas, nas quais educandos e professores estabelecem relações sociais e afetivas, sendo a "aula" o ambiente em que estas relações se solidificam e caminham em direção ao desenvolvimento significativo de habilidades cognitivas e dos aspectos sócio afetivos.

\section{Os aspectos da formação do grupo}

Observando a trajetória de pesquisa e desenvolvimento do Setor de Educação e Cultura analisamos o processo formativo de seus profissionais, coletando por livre adesão informação de doze (12) educadores que atuam em diferentes âmbitos no Setor a fim de comparar se as afirmativas teóricas e históricas condizem com a realidade docente neste processo de formação coletiva e de Hospital Educador.

O questionário apresentado ao grupo trouxe cinco (5) questões fechadas com respostas de ( ) sim ou ( ) não e quatro (4) questões abertas que permitiam dissertar e argumentar com relação a questão proposta. As respostas dadas aos questionamentos feitos, organizam o que foi mencionado anteriormente e confirmam o papel do Hospital como um espaço educador em todos os sentidos.

Os resultados nos trazem um panorama da formação inicial e continuada desses profissionais confirmando a premissa de construção do conhecimento e da busca por aprimoramento pessoal e profissional.

A formação inicial do grupo se dá em diferentes áreas do conhecimento, evidenciando a multiplicidade de saberes que se conjugam no mesmo espaço com um objetivo comum, como aponta o gráfico a seguir: 
Gráfico 1: Formação inicial

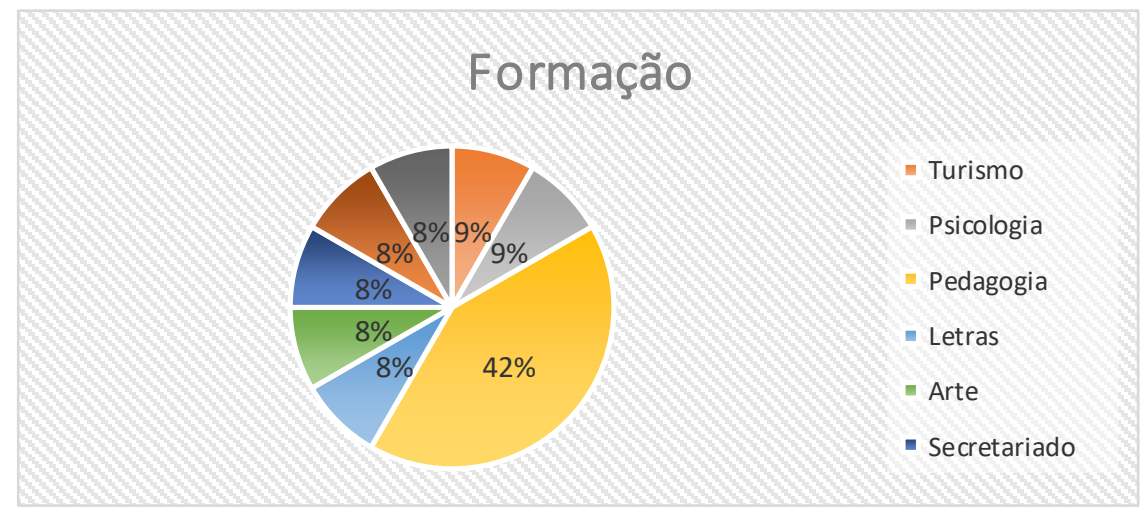

Fonte: os autores, 2020.

Analisando os aspectos da formação inicial observamos uma relação entre a licenciatura, docência e a pedagogia. O maior percentual de áreas distintas do conhecimento gerando um grupo heterogêneo que abrange diferentes campos do conhecimento. Nesse caso, o campo da pedagogia prevalece em quantitativo, mas o número de profissionais de outras áreas que atuam no Setor é significativo e for computado em conjunto.

Numa outra análise podemos observar o crescimento vertical do grupo de educadores envolvidos no campo educacional hospitalar. Quando questionados sobre especialização o percentual é bem significativo.

Gráfico 2: Percentual de especialistas

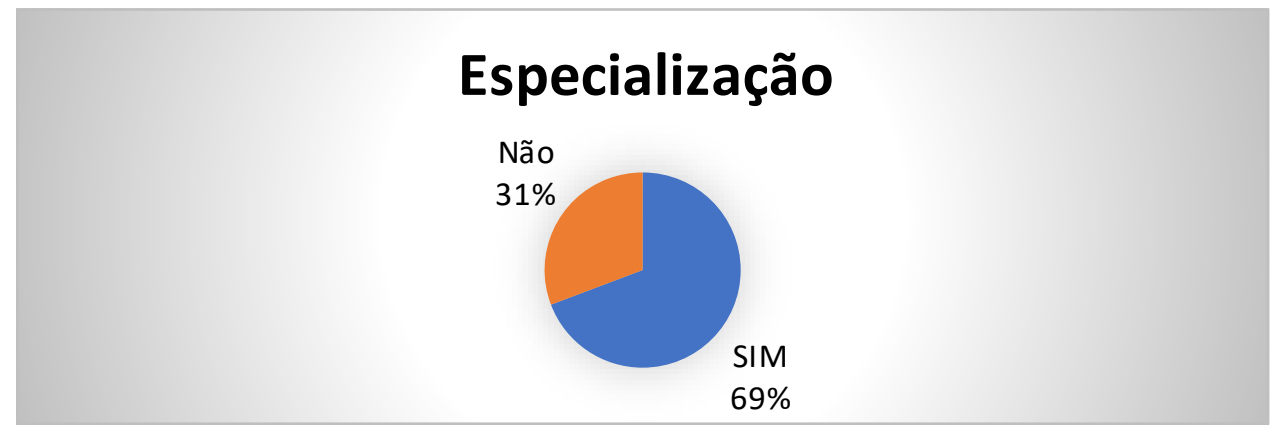

Fonte: os autores, 2020

O gráfico aponta que $69 \%$ dos educadores atuantes no Setor de Educação e Cultura possuem uma especialização, indicando que o grupo 
é bastante preocupado com sua formação. Além disso, a formação ocorre em diferentes áreas, acompanhando a tendência detectada quanto a formação inicial.

Gráfico 3: Áreas de especialização

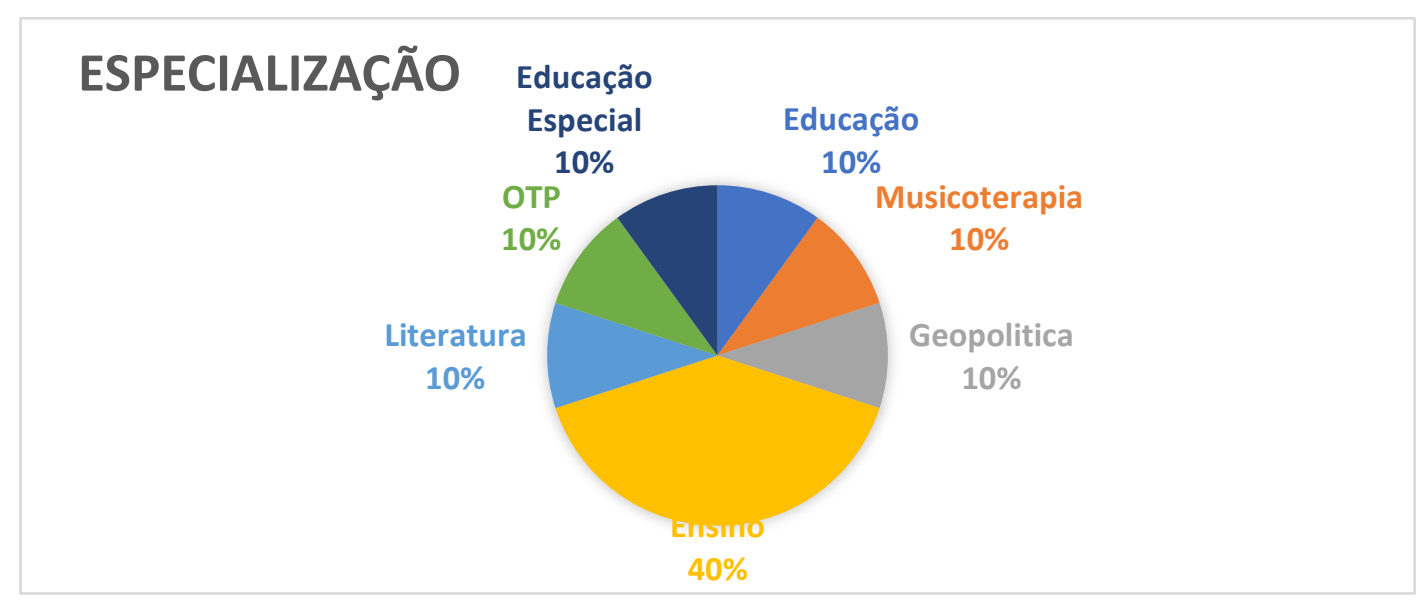

Fonte: os autores, 2020.

O gráfico 3, da área de especialização, mostra como se dá essa formação, há formações variadas, 10\% em áreas distintas e 40\% de formações que se voltam para o processo de ensino, apontando para as finalizades da ação docente no contexto específico tratado neste estudo. Ou seja, o foco nos modos de ensinar e as reflexões sobre esse processo ficam marcados no percentual de especialização dos docentes.

Quando tratamos dos níveis verticais de formação, compõe-se o seguinte gráfico: 
Gráfico 4: Pós - Graduação Mestrado e Doutorado

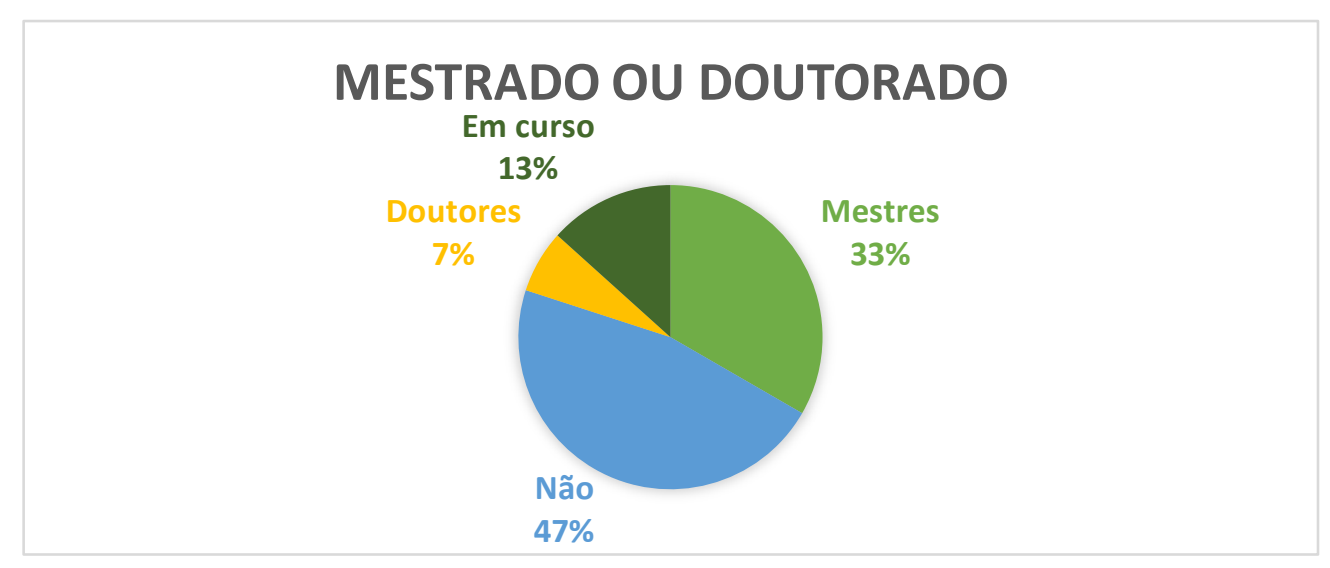

Fonte: os autores, 2020.

O gráfico 4 apresenta um percentual de profissionais que não estão neste nível de formação, mas traz também um alto percentual de profissionais que investiram em pesquisa e voltam seu olhar também para o meio acadêmico. O percentual de Mestres 33\% apresenta ainda outro dado interessante: as dissertações e pesquisas estão diretamente relacionadas ao campo de atuação, ou seja, são pesquisas que visam trazer aporte teórico para a área de atuação dos docentes envolvidos.

Identifica-se assim o espaço de atuação como um lócus de ação e pesquisa ou pesquisa e ação docente.

A segunda etapa dos questionário foi pautada em questões abertas que originaram os quadros que serão apresentados na sequência do texto. Foram quatro questões que permitiam ao educador explicar as razões de sua escolha e de seu processo formativo.

No primeiro quadro trazemos o contraponto entre formação inicial e a formação continuada, que se deu em serviço, mostrando que o grupo buscou a sua formação ao ingressar no Setor de Educação e Cultura pensando em sua ação neste espaço. 
Quadro 1: aspectos da formação docente

\begin{tabular}{|c|c|c|}
\hline Educador & $\begin{array}{l}\text { Antes do ingresso } \\
\text { no Hospital }\end{array}$ & Após o ingresso no Hospital \\
\hline Educador 1 & Especialização & $\begin{array}{l}\text { Cursos ofertados pelas secretarias, curso de } \\
\text { extensão em Atendimento Educacional em } \\
\text { Ambiente Hospitalar e Domiciliar (UFMS) }\end{array}$ \\
\hline Educador 2 & $\begin{array}{l}\text { Especialista em } \\
\text { Literatura infantil }\end{array}$ & $\begin{array}{l}\text { Bacharelado em Artes Cênicas. Comunicação não } \\
\text { violenta e mediação de leitura }\end{array}$ \\
\hline Educador 3 & Psicologia & Mestrado em Educação \\
\hline Educador 4 & Pedagogia & $\begin{array}{lllll}\text { Especialização } & \text { e } & \text { seminários } & \text { de } & \text { Pedagogia } \\
\text { Hospitalar } & & & & \end{array}$ \\
\hline Educador 5 & Secretariado & Teatro \\
\hline Educador 6 & Professor & $\begin{array}{l}\text { Seminários de Educação Hospitalar, curso de } \\
\text { extensão em Atendimento Educacional em } \\
\text { Ambiente Hospitalar e Domiciliar (UFMS), BNCO } \\
\text { e educação especial e inclusiva. }\end{array}$ \\
\hline Educador 7 & Especialização & Participou de formações relacionadas a função. \\
\hline Educador 8 & Graduação & $\begin{array}{l}\text { Especialização em musicoterapia, Formação de } \\
\text { facilitadores. }\end{array}$ \\
\hline Educador 9 & Superior completo & $\begin{array}{l}\text { Especialização em História e Ensino das artes, } \\
\text { cursos das secretarias em Educação hospitalar. }\end{array}$ \\
\hline Educador 10 & $\begin{array}{l}\text { Licenciatura e } \\
\text { Especialização }\end{array}$ & $\begin{array}{l}\text { Mestrado em Letras, participação em grupo de } \\
\text { pesquisa e cursos relacionados a área. }\end{array}$ \\
\hline Educador 11 & $\begin{array}{l}\text { Mestrado em } \\
\text { Educação com cursos } \\
\text { de formação áreas } \\
\text { especificas }\end{array}$ & $\begin{array}{l}\text { Doutorado em Educação, Participação em grupos } \\
\text { de pesquisa, curso de extensão UFMS, } \\
\text { participação em seminários e congressos. }\end{array}$ \\
\hline Educador 12 & & $\begin{array}{l}\text { UFMG - Atendimento Educacional em Ambiente } \\
\text { Hospitalar e Domiciliar } \\
\text { Grupos de estudo FAE- Direito à Educação: } \\
\text { Hospitalar e Domiciliar e HPP Preaut. }\end{array}$ \\
\hline
\end{tabular}

Fonte: os autores, 2020.

O quadro 1 enfatiza que todos os educadores investiram em sua formação após o ingresso no Setor de Educação e Cultura. Além disso, a variação de caminhos dessa formação indica uma pluralidade de escolhas que se convergem para o atendimento educacional em ambiente hospitalar.

Quando questionados sobre o que motivou a busca por formação as respostas envolvem sempre o contexto de atuação como elemento motivador para a busca de conhecimento. O quadro 2 apresenta a síntese das respostas dadas a essa questão, enfatizando a razão da busca por formação. 
Quadro 2: busca por formação

\begin{tabular}{|c|c|}
\hline Educador & O que motivou a busca por formação? \\
\hline Educador 1 & $\begin{array}{l}\text { Estudar, compartilhar particularidades e identidade do ambiente } \\
\text { hospitalar e domiciliar. Ampliar as possibilidades das práticas } \\
\text { educacionais dos estudantes em tratamento de saúde. }\end{array}$ \\
\hline Educador 2 & $\begin{array}{l}\text { A possibilidade de expandir e aprimorar o conhecimento nas áreas } \\
\text { especificas na qual atuo no hospital. }\end{array}$ \\
\hline Educador 3 & Desejo de compreender melhor aspectos do meu trabalho. \\
\hline Educador 4 & $\begin{array}{l}\text { Ampliação de conhecimentos para a gestão da prática pedagógica no } \\
\text { ambiente hospitalar. }\end{array}$ \\
\hline Educador 5 & Amor pela profissão e crescimento profissional e pessoal. \\
\hline Educador 6 & $\begin{array}{l}\text { O aprimoramento para melhor atender os estudantes e relacionamento } \\
\text { interpessoal. }\end{array}$ \\
\hline Educador 7 & $\begin{array}{l}\text { Pela oportunidade de se instrumentalizar um pouco mais, ter acesso a novos } \\
\text { conteúdos, aumentar o repertório para atendimento junto as famílias. }\end{array}$ \\
\hline Educador 8 & $\begin{array}{l}\text { O trabalho realizado na humanização e o trabalho realizado com a } \\
\text { música. }\end{array}$ \\
\hline Educador 9 & $\begin{array}{l}\text { Melhoria na atuação profissional tanto no atendimento da escolarização } \\
\text { hospitalar quanto na atuação em sala na disciplina de sociologia. }\end{array}$ \\
\hline Educador 10 & $\begin{array}{l}\text { O que move o processo de formação é a paixão pelo contexto de atuação } \\
\text { (hospital), a busca por novas alternativas de ensino e a crença de que a } \\
\text { formação docente aliada a boas práticas é capaz de gerar uma educação } \\
\text { mais eficiente e efetiva que se volta para as necessidades do sujeito. }\end{array}$ \\
\hline Educador 11 & $\begin{array}{l}\text { A melhoria e diversificação da prática docente tendo em vista a diversidade } \\
\text { no hospital, diversidade que diz respeito não somente a questões orgânicas, } \\
\text { mas também étnicas, culturais, linguísticas, entre outras. }\end{array}$ \\
\hline Educador 12 & $\begin{array}{l}\text { Para garantir o direito à educação de crianças e jovens hospitalizados. } \\
\text { Levar para as famílias a informação que mesmo hospitalizados, as } \\
\text { crianças e os jovens têm o direito garantido em estudar. }\end{array}$ \\
\hline
\end{tabular}

Fonte: os autores, 2020.

Analisando o quadro 2 observamos uma recorrência de menção ao espaço de atuação, todos os sujeitos enfatizam o trabalho com a criança e o adolescente em tratamento de saúde como elemento motivador para sua busca por formação e conhecimento na área de atuação. Há uma vinculação muito forte do sujeito com o estudo e com o seu local de trabalho.

Destaca-se a busca por formação como fator atrelado a qualidade do trabalho desenvolvido com as crianças e adolescentes hospitalizados, suas famílias e até mesmo funcionários do hospital. Há por parte de 
todos os membros uma preocupação com a qualidade da informação e do serviço educativo que é desenvolvido. A atuação no espaço hospitalar aparece no discurso dos educadores como elemento motivador para a busca de conhecimento e aperfeiçoamento técnico e pessoal. De acordo com Imbernón (2011, p. 36) "A profissionalização do professor está diretamente ligada ao exercício de sua prática profissional" corroborando com o que indica o relato dos educadores. Ainda sobre este aspecto, o autor aponta que:

Se a prática é um processo constante de estudo, de reflexão, de discussão, de experimentação, conjunta e dialeticamente com o grupo de professores, se aproximará da tendência emancipadora, crítica, assumindo um certo grau de poder que repercute no domínio de si mesmos. (IMBERNÓN, 2011, P. 36).

Outro ponto importante e que carrega a significação do contexto e a bagagem de conhecimento e de vínculo dos sujeitos com a área de atuação refere-se aos aspectos que consideram importantes na formação para a atuação neste contexto. O quadro 3 demonstra claramente o que os educadores apontam como relevante em relação aos a spectos da formação. 
Quadro 3: formação do educador - professor no hospital

\begin{tabular}{|c|c|}
\hline Educador & $\begin{array}{l}\text { Quais aspectos você acha importantes na formação do Educador - } \\
\text { Professor no hospital? }\end{array}$ \\
\hline Educador 1 & $\begin{array}{l}\text { Um dos aspectos importantes na formação do professor é estar amplamente } \\
\text { aberto a descobrir formas de melhorar sua atuação com os estudantes. } \\
\text { Questionar sua prática, compartilhar ações, participar do trabalho da equipe } \\
\text { multidisciplinar no intuito de contribuir ainda mais para o bem estar e } \\
\text { desenvolvimento dos estudantes e pacientes. }\end{array}$ \\
\hline Educador 2 & $\begin{array}{l}\text { A respeito do meu trabalho considero importante todas as práticas/ cursos com } \\
\text { quais tenho contato, pois para além do meu trabalho como educadora, também } \\
\text { desenvolvo um trabalho como facilitadora no Núcleo de Humanização, então, } \\
\text { os cursos relacionados à arte e comunicação me possibilitam novas ferramentas } \\
\text { tanto para trabalhar nas oficinas com as crianças (parte cultural) quanto com } \\
\text { os colaboradores. A arte e a cultura sem dúvida, são um aspecto muito } \\
\text { importante no trabalho que desenvolvo. }\end{array}$ \\
\hline Educador 3 & $\begin{array}{l}\text { Que o profissional tenha conhecimento de variados tópicos de diversas } \\
\text { áreas do saber e não apenas da especialidade que se formou. Que seja } \\
\text { curioso e saiba compartilhar sua curiosidade. }\end{array}$ \\
\hline Educador 4 & $\begin{array}{l}\text { omprometimento com o cuidado: do direito à educação do estudante; com } \\
\text { continuidade dos estudos e com o preparo das aulas do estudante. }\end{array}$ \\
\hline Educador 5 & $\begin{array}{l}\text { tinuar seus estudos e poder ver o } \\
\text { la escolha da futura profissão). }\end{array}$ \\
\hline Educador 6 & $\begin{array}{l}\text { A atualização e a ampliação da visão profissional para melhor atender as } \\
\text { especificidades dos educandos. }\end{array}$ \\
\hline Educador 7 & $\begin{array}{l}\text { Acredito que o educador no contexto hospitalar, para além de ter consciência } \\
\text { sobre alguns procedimentos técnicos, precisa de uma postura diferenciada } \\
\text { para se relacionar com o aluno/paciente. Precisa estar capacitado para lidar } \\
\text { com as especificidades de cada aluno, ter destreza, flexibilidade e } \\
\text { sensibilidade para lidar com cada situação especial que se depara. }\end{array}$ \\
\hline Educador 8 & $\begin{array}{l}\text { Vinculo com o paciente, criatividade didática, envolvimento familiar, ser } \\
\text { analógico X tecnológico, expressão artística. }\end{array}$ \\
\hline Educador 9 & $\begin{array}{l}\text { os onde o professor possa explorar } \\
\text { com ampla variedade de materiais } \\
\text { orciona. }\end{array}$ \\
\hline Educador 10 & $\begin{array}{l}\text { Consciência crítica, criatividade, proatividade, senso ético e de responsabilidade, } \\
\text { capacidade de ajuste as necessidades do contexto e dos sujeitos que atende, } \\
\text { competência para adaptar-se e adaptar seus fazeres ao espaço de atuação. }\end{array}$ \\
\hline Educador 11 & $\begin{array}{l}\text { Formação personalizada tendo em vista a necessidade dos estudantes } \\
\text { atendidos, daí a necessidade de cursos nas diversas áreas do conhecimento, } \\
\text { mas com exploração de recursos e materiais adequados ao uso no hospital com } \\
\text { sua exigência de higienização. Mais do que temas, busca-se uma formação que } \\
\text { permita a flexibilização curricular, avaliativa e metodológica que a prática } \\
\text { hospitalar exige para cumprir o objetivo de garantir a continuidade dos } \\
\text { estudos. Desta forma, ressalto a importância da formação junto ao próprio } \\
\text { grupo atuante, visto que cada hospital compõem um lócus único de trabalho. }\end{array}$ \\
\hline Educador 12 & $\begin{array}{l}\text { A importância da formação de professores para atuar no meio hospitalar, deve } \\
\text { ser voltado para a humanização, profissionais que saibam olhar seu aluno } \\
\text { como um todo e que trabalhem de forma interdisciplinar, ressalto o que Silva } \\
\text { (2003) apresenta sobre a função do educador no hospital, onde o profissional } \\
\text { deve proporcionar diferentes situações significativas de aprendizagem que } \\
\text { contribuam no processo de reabilitação e consequentemente no } \\
\text { desenvolvimento dos pacientes. Os profissionais que atuam com esse público, } \\
\text { precisam oportunizar momentos, do aprender a aprender. }\end{array}$ \\
\hline
\end{tabular}

Fonte: os autores, 2020. 
Ao apontar os aspectos relevantes na formação do educador hospitalar os sujeitos indicam um conjunto de fatores que elencados no quadro 3 , trazem a tona o que cada um individualmente valoriza desse constructo coletivo de formação docente. Trata-se de um conhecimento pedagógico que se reconstruiu e ressignificou diante do contexto de atuação e da formação entre pares. Os docentes apontam aspectos importantes e interessantes na formação, aspectos que envolvem categorias do desenvolvimento humano, técnico, teórico que extrapolam o conhecimento acadêmico das áreas iniciais de formação.

Ao analisarmos criteriosamente as repostas a questão: Quais aspectos você acha importantes na formação do Educador - Professor no hospital?, identificamos, no rol de respostas, aspectos que se completam e se somam a pontos de convergência com o que afirma Imbernón (2011) sobre as linhas de formação permanente:

1. A reflexão prático-teórica sobre a própria prática mediante análise; a compreensão, a interpretação e a intervenção sobre a realidade. A capacidade do professor gerar conhecimento pedagógico por meio da prática educativa.

2. A troca de experiência entre iguais para tornar possível a atualização em todos os campos de intervenção educativa e aumentar a comunicação entre professores.

3. A união da formação a um projeto de trabalho.

4. A formação como estímulo crítico ante práticas profissionais como a hierarquia, o sexismo, a proletarização, o individualismo, o pouco prestigio, etc, e prráticas sociais como a exclusão, a intolerância, etc.

5. O desenvolvimento profissional da instituição educativa mediante o trabalho conjunto para transformar essa prática. (IMBERNÓN, 2011, p.50).

Dessa forma, ficam as evidências de que há um processo reflexivo dos sujeitos sobre sua prática quando analisamos o conjun to de conceitos e de trajetórias de formação de um grupo relativamente significativo que visa trazer o seu contexto de trabalho uma prática diferente, que é refletida e ressignificada propondo um modo de ensinar e aprender distinto dos moldes tradicionais. 


\section{Considerações finais}

O texto aqui apresentado trouxe a discussão de aspectos da formação dos docentes em um contexto múltiplo e complexo, a escolarização em hospitais. Enfatizamos que tal formação é plural e se volta para as necessidades que o trabalho no hospital exige. Compreendemos que muito além de especialistas em educação hospitalar o que apresentamos é uma formação humana, humanista, humanizadora e dialógica que foca sua lente nas especificidades do desenvolvimento da capacidade de lidar e acolher o outro, neste caso, crianças, adolescentes, familiares, equipe de saúde e educadores com os quais interagimos diariamente.

Apontamos que neste contexto, muito mais do que em qualquer outro, o processo educacional revela e desenvolve conhecimentos e habilidades, exigindo um professor dinâmico, criativo, aberto a múltiplas possibilidades de ação e interação. Sendo assim, compreendemos que o professor deve ser o inspirador do aprendizado. Para tanto, deve pesquisar, inovar e incrementar seus conhecimentos pedagógicos, expandir sua cultura geral e procurar conhecer e desenvolver novas técnicas de ensino. No hospital, a diversidade diz respeito a aspectos que singularizam os atendimentos e demandam um olhar sensível dos docentes para acolhimento das diferenças sem dar-se espaço a discriminações de qualquer ordem, ressaltamos ainda que cada enfermaria configura uma cultura própria, e exige ação conjunta entre o campo da educação e saúde, campos interligados no ambiente hospitalar, onde a "escola" reinventa-se. A formação docente depreende um desenho que permita a flexibilização curricular, metodológica e avaliativa para suprir necessidades singulares e garantir o direito à educação, sob compreensão de que a afetividade, o respeito e a ética permeiam todo o ato educativo. 


\section{Referências}

BRASIL. Decreto Lei $n .1044 / 69$, art. $1^{\circ}$, que dispõe sobre tratamento excepcional para alunos portadores de afecções. Brasília, 1969.

BRASIL. Constituição Federal. Brasília, Senado Federal, 1988.

BRASIL. Ministério da Educação. Lei n. 9.394/96. Lei de Diretrizes e Bases da Educação Nacional. Brasília. 1996.

BRASIL. Lei n. 8.069, de 13 de julho de 1990. Dispõe sobre o Estatuto da Criança e do Adolescente e dá outras providências.

BRASIL. Conselho Nacional de Direitos da Criança e do Adolescente. Resolução $N^{\circ}$ 41, de 13 de outubro de 1995. DOU, Seção 1, de 17/10/1995.

BRASIL. Classe hospitalar e atendimento pedagógico domiciliar: estratégias e orientações. Secretaria de Educação Especial. Brasília: MEC; SEESP, 2002.

BRASIL. Política Nacional de Educação Especial na Perspectiva da Educação Inclusiva. MEC, 2008.

BRASIL. Alteração da Lei n. 9.394/96 pelo texto da Lei $n^{\circ} 13.716$, de 24 de setembro de 2018.

CARREIRA, Denise. O direito à educação e à cultura em hospitais: caminhos e aprendizagens do Pequeno Príncipe. Curitiba [Paraná]: Associação Hospitalar de Proteção à Infância Dr. Raul Carneiro, 2016.

FREIRE, Paulo. Política e Educação. São Paulo, Cortez, 1993.

FREIRE, Paulo. Professora Sim, Tia Não - cartas a quem ousa ensinar, $4^{\mathrm{a}}$ ed. São Paulo: Olho d'Água, 1994.

FREIRE, Paulo. Pedagogia da Autonomia: saberes necessários à prática educativa. São Paulo, Paz e Terra, 1996.

FREIRE, Paulo. Pedagogia da esperança: um reencontro com a pedagogia da autonomia. Rio de Janeiro, Paz e Terra. 1998.

FREIRE, Paulo. Papel da educação na humanização. In: Rev. da FAEEBA, Salvador, $\mathrm{n}^{\circ} 7$, jan. / junho, 1997.

FREIRE, Paulo. Pedagogia da indignação: cartas pedagógicas e outros escritos. São Paulo: Editora UNESP, 2000b. 
FREIRE, Paulo. Educação e Mudança. 34ª ed. -São Paulo: Paz e Terra, 2011.

FREIRE, Paulo, FAUNDEZ Antônio. Por uma pedagogia da pergunta. $7^{\mathrm{a}}$ ed. -São Paulo: Paz e Terra, 2011.

IMBERNÓN, Francisco. Formação docente e profissional: formar-se par a mudança e a incerteza. 9a ed. - São Paulo: Cortez, 2011.

RANGEL, Mary. Educação, Porto Alegre, v. 32, n. 1, p. 59-64, jan./abr. 2009.

Recebido em março de 2020.

Aprovado em setembro de 2020. 